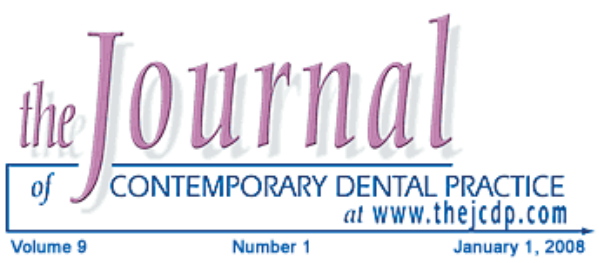

\title{
Developing Lifetime Relationships with Patients: Strategies to Improve Patient Care and Build Your Practice
}

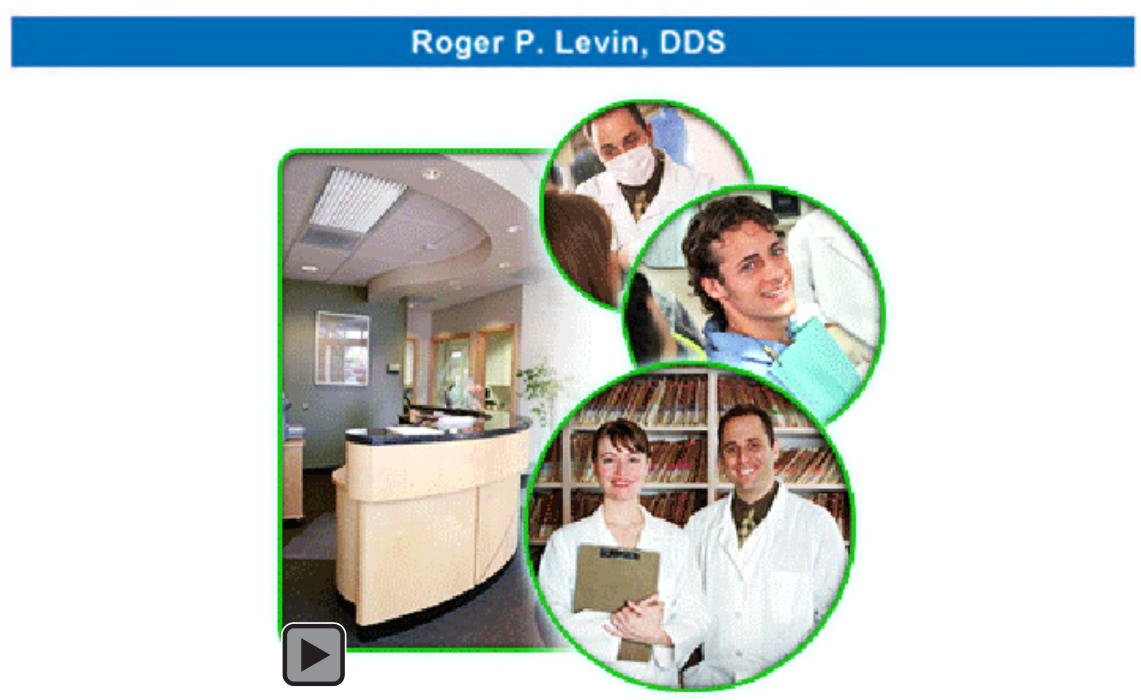

\section{Abstract}

Aim: The purpose of this article is to describe three strategies to build a thriving, patient-centered practice and promote oral health throughout a patient's lifetime.

Background: Compared to previous decades, more dental patients are "shopping around" for dental care and changing dental practices. This trend is due to factors such as acceptance of dental insurance, more comprehensive service offerings by other dentists, and effective marketing campaigns by other dental offices.

Findings: Delivering customer service exceeding patient expectations ("WOW" service), advocating patient education, and developing customized home care regimens will help lead to long-term patient retention and promote optimal patient care.

Discussion: A dental team making relationship-building a priority conveys respect for their patients' time and well-being. Once trust has been established patients are more likely to be receptive to oral health education and become more compliant with home care regimens. Since a patient's oral health status will likely change over time, it's important to make education and customized treatment planning an integral part of each visit.

Conclusions: By demonstrating a strong commitment to customer service, education, and home care, patients recognize the care providers in a dental practice are interested in their well-being rather than simply treating problems.

(c) Seer Publishing 
Clinical Significance: If patients recognize a dental practice is focused on prevention and at-home oral health care, they are more likely to partner with that practice for a lifetime of excellent oral health care.

Keywords: Patient-centered practice, comprehensive service, patient education

Citation: Levin RP. Developing Lifetime Relationships with Patients: Strategies to Improve Patient Care and Build Your Practice. J Contemp Dent Pract 2008 January; (9)1:105-112.

\section{Introduction}

The following is a mock dialog between a fictitious dentist and the front desk coordinator when a patient cancelled her appointment:

"What happened to Mrs. Jones?" asked Dr. Smith.

"She cancelled her appointment," replied the front desk coordinator.

"That's unlike her. Did she give a reason?"

"No, but she requested that a copy of her dental records be sent to a Dr. Miller."

Dr. Smith was troubled for this was the third long-term patient to the leave the practice in the last ten days. This was difficult to understand why this was happening since he felt his practice provided exceptional patient care at reasonable fees and the office was in a favorable location.

Dr. Smith didn't have time to dwell on Mrs. Jones' departure for he had another patient waiting for him. After speaking with the hygienist for a moment, he

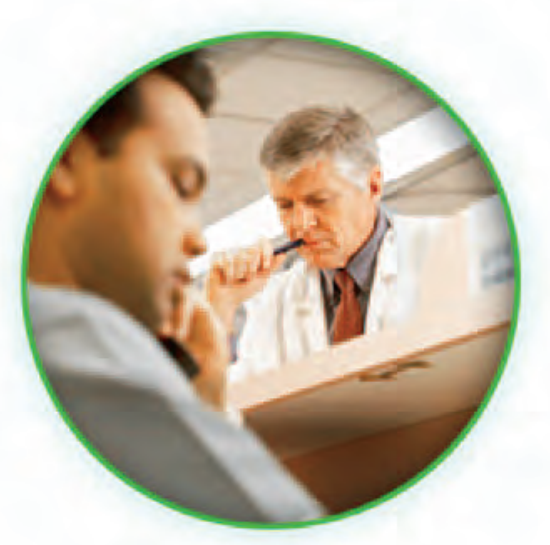

proceeded to the treatment room and greeted the patient.

"Hi, Mrs. Adams. How are you today?"

"Fine." She replied.

"Well, according to your X-ray, it looks like you may have a cavity. Let's have a look-see..."

Dr. Smith's story is hardly unique. In recent years, more patients are shopping around and changing practices compared to previous decades. Some reasons for this "shopper's mentality" include variations in dental insurance acceptance, more comprehensive service offerings by other dentists, and effective marketing campaigns by other dental offices.

There are three interrelated strategies to keep a patient like the fictitious Mrs. Jones in a dental practice.

1. Provision of customer service beyond a patient's expectations

2. Advocate and provide patient education

3. Provide customized treatment planning for lifetime care

Unfortunately, Dr. Smith didn't attempt any of these in his interaction with Mrs. Adams. "Hi" was the extent of his conversation with the patient before he conveyed the bad news about her cavity. Dr. Smith may provide great clinical care, but his chair side manner leaves a lot to be desired.

In today's highly competitive marketplace, basic customer service is no longer good enough. Patients have more options for their dental care than ever before. The Internet makes finding 
another nearby dental practice quick and easy. Most dental practices have websites that explain their treatment philosophy, list need-based and elective services, and provide information about the dentist and the support staff.

Lackluster customer service can drive patients away and should be avoided. In contrast building a patient-oriented practice fosters trust, provides essential patient education, and offers customized treatment plans to meet patients' oral health needs throughout their lifetime.

\section{The "Wow" Customer Service Factor} Amazon.com CEO Jeff Bezos described exceptional customer service this way: "We see our customers as invited guests to a party, and we are the hosts. It's our job every day to make every important aspect of the customer experience a little bit better." "WOW" customer service is about exceeding patient expectations, going the extra mile, and doing all the little things that add up to an overwhelming positive experience.

Dentistry is a relationship business. The goal is to "WOW" every patient who walks through the door every day, every time, without exception. The following are some action steps that can help dental office personnel achieve the "WOW" factor:

- Greet Patients Enthusiastically. Be sure that office team members greet all patients by name. Everyone likes hearing the sound of his or her name.

- Smile. In the hectic pace of a dental practice it is possible for office team members to forget to smile even though they are the smile experts. Remember, patients are guests in the dental practice and should be treated as such.

- Personalize. Each patient conversation should begin with something personal as opposed to proceeding immediately with clinical conversation. Take the time to talk to each patient about something in his or her life. Avoid being like the fictitious Dr. Smith who after a quick hello moved right to the clinical examination.

- Think Special. Do something special for patients. What distinguishes one dental practice different from other practices? It might be offering coffee in the reception area,

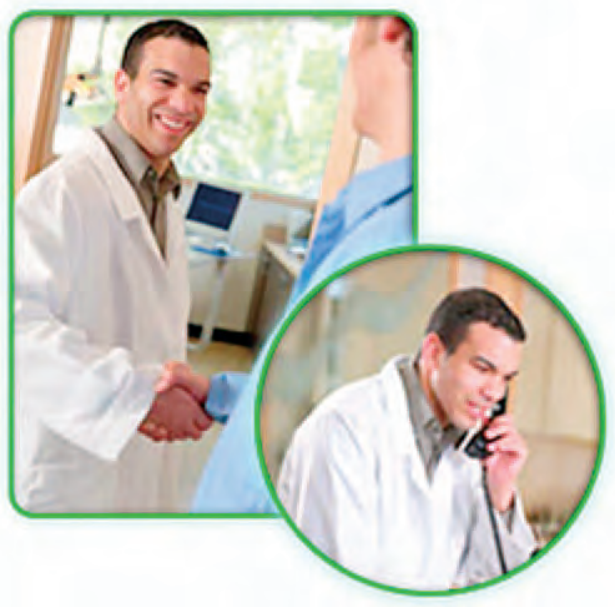

sending notes or greeting cards for special occasions like birthdays, graduation, or recognition of special achievement. Anything that lets patients know the office team cares is worthwhile.

- Show Interest. Learn new information about patients at every visit such as identification of the members of their family, their job, travel experience, and personal interests. Make notes of the conversation somewhere in the patient's record so that you can reference it at a future visit.

- Make "Thank You" Calls. Call patients who refer their friends, family, and neighbors. The gift of a referral certainly deserves not only a thank you note but also a personal call which also encourages these patients to refer again.

\section{Patient Education}

Educating patients on dental care topics helps emphasize their role in oral health outcomes. Having a dental exam and prophylaxis at least twice a year is critical, but long-term results depend largely on what patients do at home between visits. Many patients are not aware of the effects of home care, lifestyle habits, and diet on their oral health. For example, a recent survey of patients in England showed only 6\% of respondents were aware of the relationship between tobacco use and periodontal disease. ${ }^{2}$

There are several reasons why education should be a component of each and every visit. First, research has shown improved outcomes following individual patient education. ${ }^{3}$ Repetition increases the retention of information. Another important reason for continuous patient education 


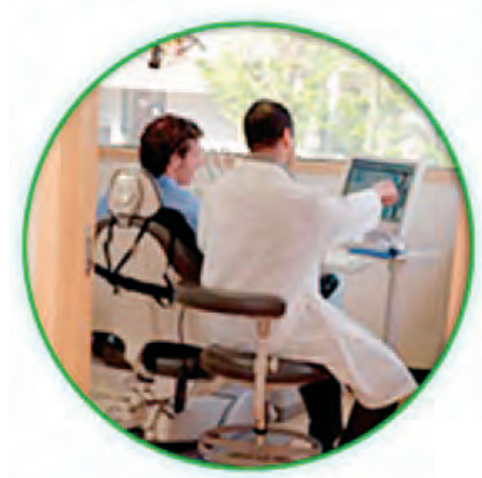

is the change in a patient's oral health needs accompanying various life stages. For example, a female patient may need information on orthodontics in her teens, pregnancy gingivitis in her 20's, tooth whitening in her 40's, and drug-induced xerostomia in her 60's. Finally, researchers are continuously discovering new information about oral health, particularly regarding links to systemic health. ${ }^{4}$ Obtaining the information from you first will help patients put this new knowledge in the appropriate context.

Active learning, such as having patients practice brushing and flossing technique in the operatory, is an excellent way to instruct patients. Other effective approaches include:

- Using visual technology (intra-oral camera, digital radiography, etc.) to highlight the restorative needs of patients.

- Showing patients brief educational video podcasts on an ipod or computer. A research study showed greater plaque removal when patients watched an instructional video versus reviewing a leaflet on power brushing technique. ${ }^{5}$ (Please go to www.thejcdp.com and click on the links for brief brushing and flossing video podcasts).
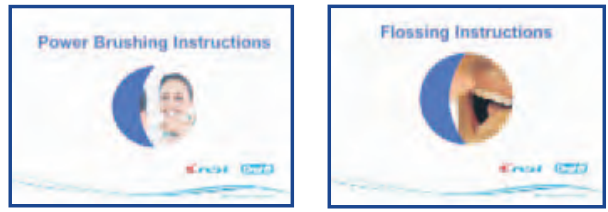

- Developing a patient education section of a dental office website. Many dental associations and manufacturers already have materials available online, so developing content for your site can be as simple as providing links to relevant topics.

- Conducting a patient seminar on topics of interest to your patients, such as "oral health for diabetic patients" or "oral side effects of medication for cardiovascular disease." Several organizations have scripted presentations available for this purpose.

- Recommending products that reinforce good habits. For example, a new Oral-B ${ }^{\oplus}$ power toothbrush (Triumph ${ }^{\mathrm{TM}}$ with SmartGuide ${ }^{\mathrm{TM}}$ ) has a wireless remote display with a timer to track brushing time, a visual quadrant timer showing patients when to change quadrants, and a visual pressure sensor that alerts them if too much pressure is applied. ${ }^{6}$ These features reinforce good brushing technique at home.

Basic instructional tools such as written material are also useful. Free downloadable patient education materials in 17 languages can be found at the dentalcare.com website. ${ }^{7}$ These materials can be customized for an individual practice in terms of the practice name and address before printing and distribution to patients.

Customized Treatment Plans For Lifetime Care In addition to ongoing patient education, patients need safe and effective products for home care. While products are typically marketed and evaluated individually, patients typically use a regimen of products so professionals should consider how products will work together. Patients typically have at least two products in their home care regimen, a toothbrush and dentifrice. Recommending a clinically proven power toothbrush (e.g., oscillating-rotating) ${ }^{8}$ and antimicrobial toothpaste (e.g., stannous fluoride) ${ }^{9}$ is a simple way to enhance plaque control, a benefit virtually every patient needs. A research study showed using a therapeutic rinse after brushing with an antiplaque toothpaste further inhibited plaque regrowth. ${ }^{10}$ Of course, flossing should always be part of the basic oral hygiene routine. As patients move through various life stages, home care regimens will likely need to be adjusted (Table 1).

When discussing home care regimens with patients, several strategies to promote compliance can be used:

- Facilitate Product Availability. Home care products such as power toothbrushes or tooth whitening products made available at a reduced price in the dental office makes 
Table 1. Common home care regimens for typical life stages.

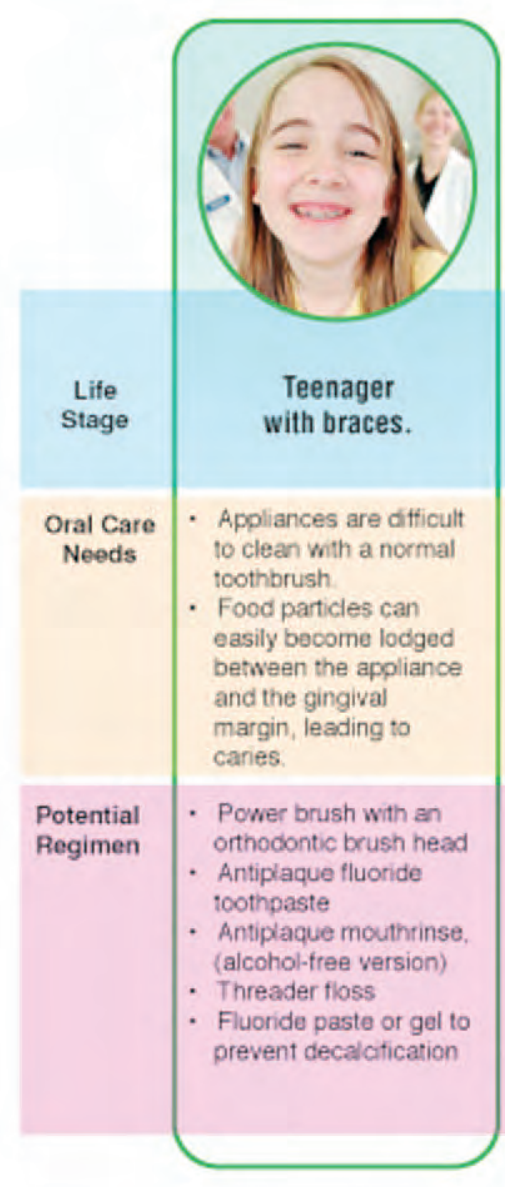

the purchase of oral health products very convenient, saves patients the time and expense of driving somewhere else, and ensures the acquisition of the right product. In-office purchases provide the opportunity to instruct patients on proper usage before they leave the office to ensure they get the maximum benefit.

- Financial Considerations. Most home care products and treatments are available at a range of price points. While patient income should be taken into account, home care options shouldn't automatically be limited to those corresponding with their economic status. A patient with a high dental IQ and a small disposable income may choose premium home care products, while another patient with a larger disposable income may prefer only basic options.

- Patient Values-based Motivation. While the oral health of patients is the top priority of dentists, patients may be more interested in

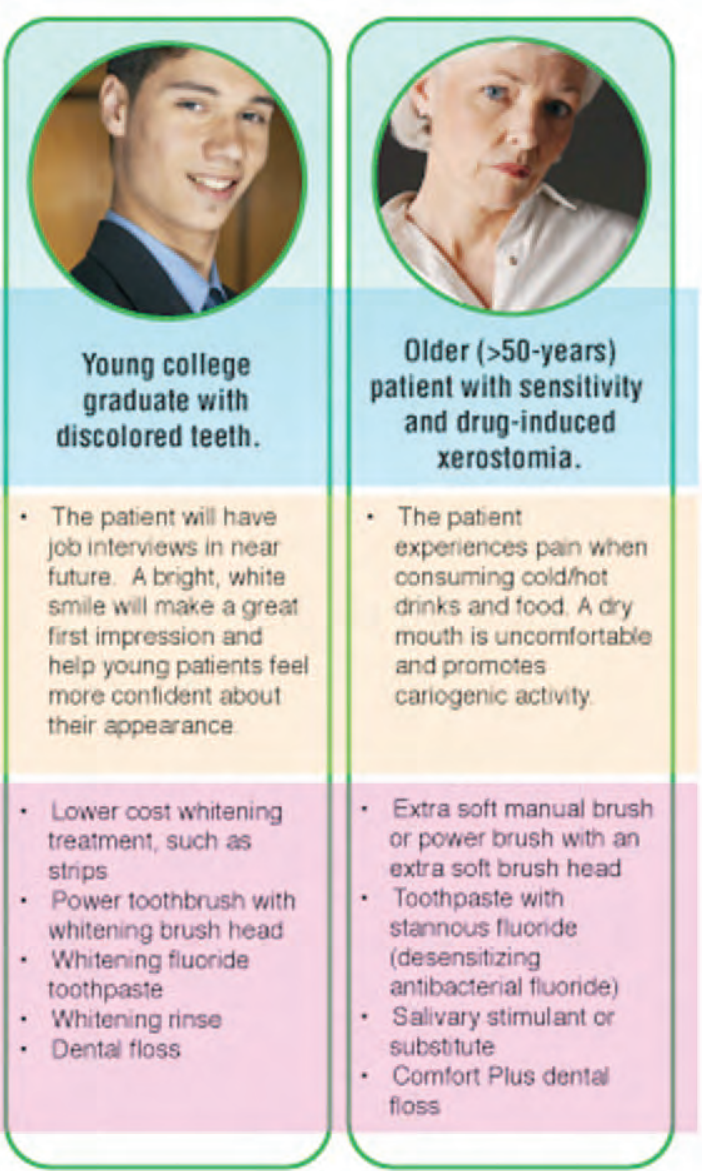

having white teeth, pleasant breath, and a rapid oral hygiene routine. It is advisable to incorporate each patient's individual wants and needs in a home care 'pep talk' to help promote patient compliance. Motivational interviewing is a good technique to practice this skill. ${ }^{1}$

\section{Conclusion}

Demonstrating a strong commitment to customer service, education, and home care results in patient appreciation of the interest the dental team has in their well-being rather than simply treating problems. When patients recognize the staff in a dental practice is focused on prevention and at-home oral health care, they will more likely partner with the practice for a lifetime of excellent oral health care. 


\section{References}

1. http://www.brainyquote.com/quotes/authors/j/jeff_bezos.html retrieved in August 2007.

2. Lung ZH, Kelleher MG, Porter RW, Gonzalez J, Lung RF. Poor patient awareness of the relationship between smoking and periodontal diseases. Br Dent J. 2005 Dec:10;199(11):731-7.

3. Sniehotta FF, Araújo Soares V, Dombrowski SU. Randomized controlled trial of a one-minute intervention changing oral self-care behavior. Dent Res. 2007 Jul;86(7):641-5.

4. Guynup S. Our Mouths, Ourselves. Sci Am. 2006 (Suppl); 3-5.

5. Renton-Harper P, Addy M, Warren P, Newcombe RG. Comparison of video and written instructions for plaque removal by an oscillating/rotating/reciprocating electric toothbrush. J Clin Periodontol. 1999;26:752-6.

6. Walters PA, Cugini M, Biesbrock AR, Warren PR. A novel oscillating-rotating power toothbrush with SmartGuide ${ }^{\mathrm{TM}}$ : designed for enhanced performance and compliance. J Contemp Dent Pract. 2007 May;(8)4:001-009.

7. Jensen ME. Internet Resources for the New Dentist. Mentor Sep 2006; 13-16.

8. Robinson PG, Deacon SA, Deery C, Heanue M, Walmsley AD, Worthington HV, Glenny AM, Shaw WC. Manual versus powered toothbrushing for oral health. Cochrane Database Syst Rev. 2005 Apr 18;(2):CD002281.

9. Baig AA. A novel dentifrice technology for advanced oral health protection: a review of technical and clinical data. Compend Contin Educ Dent. 2005;26 (supp 1):4-11.

10. White DJ, Kozak KM, Barker ML. Antiplaque efficacy of combined chemotherapeutics. J Dent Res. 2007;86 (Spec Iss). Abstract 1072.

11. Gache P, Fortini C, Meynard A, Reiner Meylan M, Sommer J. Motivational interviewing: some theoretical aspects and some practical exercises. Rev Med Suisse. 2006 Sep 27;2(80):2154, 2156-62.

\section{About the Author}

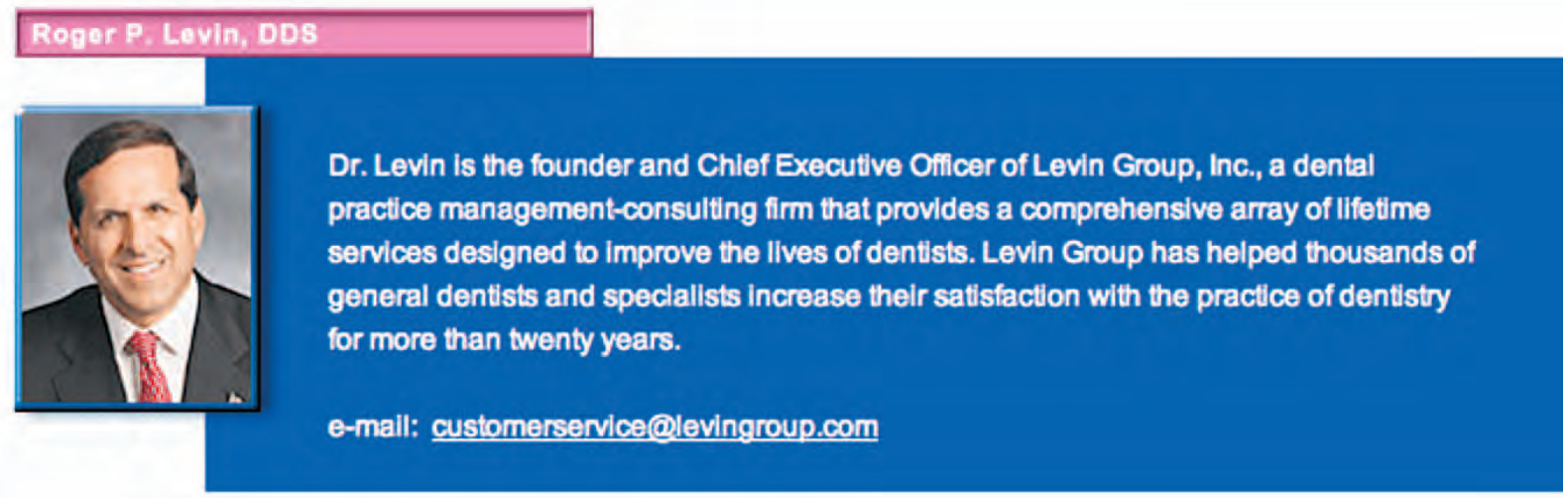

